\title{
Hybrid Sling for the Treatment of Concomitant Female Urethral Complex Diverticula and Stress Urinary Incontinence
}

This article was published in the following Dove Press journal: Research and Reports in Urology

William Eduardo Ito

Paulo Ricardo Pastre Marcon

André Fernando Tannouri Garbin

Marco Aurélio Freitas Rodrigues

Sílvio Henrique Maia de Almeida (D)

Surgery Department, Urology Discipline, Universidade Estadual de Londrina,

Londrina, PR, Brazil
Correspondence: Sílvio Henrique Maia de Almeida

Tel/Fax +55-43-3377/800

Email salmeida@sercomtel.com.br

\begin{abstract}
This study aims to present an alternative technique with the use of a transobturator hybrid sling (autologous fascia lata with a synthetic sling) in two patients with complex urethral diverticulum (CUD), urinary stress incontinence (SUI) and a large incisional infraumbilical hernia. Staged procedures could be performed, but considering the risk of persistence or worsening SUI, and no standard management strategy of SUI associated with CUD; simultaneous treatment was proposed. It is preferable to use autologous materials in such cases. However, the presence of incisional hernia protruded with its content covering the suprapubic area prohibits the retropubic sling technique due to visceral lesion risk. The diverticulum and SUI were repairs in the same surgery using a hybrid transobturator. The technique used for obtaining the fascia lata followed the literature, and a $6 \mathrm{~cm}$ segment was acquired. The patients were re-prepared in a lithotomy fashion, and diverticulectomy was performed. The segment of fascia lata was fixed to the mesh and sling was manipulated so that its middle part (fascia) rested directly below the urethra. After 6 months post-operatively, patients referred significant improvement in urinary symptoms. Patients have not had any storage symptoms, International Consultation on Incontinence Questionnaire - Short Form = zero, no SUI, and have not had any mesh-related complications. In conclusion, the present study evaluated a new technique for the treatment of CUD with SUI in a particular clinical scenario. Other studies with extended follow-up periods and larger sample sizes should be performed in this subset of patients.
\end{abstract}

Keywords: urethra, diverticulum, stress urinary incontinence, sling, diverticulectomy, fascia lata

\section{Introduction}

Urethral diverticulum (UD) affects 17.8 in 1,000,000 women per year ${ }^{1}$ and may result in an ample spectrum of symptoms and anatomic shapes varying from simple or extensive to complex. Complex UD (CUD) may spread partially around the urethra (sac-like configuration) or circumferentially about the urethra. ${ }^{2}$

The exact prevalence of CUD is unknown, but Nickels et $\mathrm{al}^{3}$ found a prevalence of $25 \%$ in a cohort of 43 patients. CUD can be challenging to repair, as there have been a variety of techniques described for CUD correction and a limited number of studies describing the results after repair. ${ }^{4,5}$

UD can also present in combination with stress urinary incontinence (SUI), with overall reports between $10 \%$ and $57 \%, ;^{5,6}$ additionally, $50 \%$ to $60 \%{ }^{4-6}$ of cases require surgical treatment, especially for symptomatic patients. Simultaneous treatment is 
possible, but it is preferable to use autologous materials in such cases, and surgeons must avoid synthetic slings ( $\mathrm{SSs})^{7,8}$ due to the risk of urethral erosion.

Because the use of autologous rectus fascia is safer than that of conventional SSs, El-Gamal et $\mathrm{al}^{9}$ demonstrated a novel transobturator hybrid sling designed with polypropylene mesh and a strip of autologous rectus fascia in its middle part. Early results were reported for the use of this sling, and this new technique showed good short-term efficacy for the treatment of female SUI. However, in particular, the retropubic sling technique is prohibited, due to the risk of visceral lesions, in cases where the incisional hernia protruded, with its content covering the suprapubic area.

Therefore, the purpose of this study is to introduce an alternative technique with the use of a transobturator (TOT) hybrid sling (autologous fascia lata with an SS) for the treatment of CUD, with symptomatic SUI in obese patients and with large incisional hernias at previous laparotomy sites.

\section{Case Reports}

\section{Patient I}

A 63-year-old female developed dysuria, dyspareunia, urethral purulent discharge, and SUI daily (several drops two spoons full) for 6 months. She used 3 pads per day and had an International Consultation on Incontinence Questionnaire - Short Form (ICIQ-short form) score of 15.

Physical examination showed an incisional hernia occupying the full extent of the median incision scar from anterior surgery and the projection of umbilical scar to the pubic symphysis (due to anterior colectomy) with the presence of bowel and omentum.

Vaginal examination showed a loss of dribbling upon coughing, a grade 2 cystocele, and a small mass approximately $2.5 \mathrm{~cm}$ in size that could be palpated in the anterior vaginal wall, without mobility and with fibroelastic consistency; there was mild compression pain and elimination of purulent discharge.

The patient underwent a vaginal ultrasound showing a cystic lesion close to the urethra without defined continuity with the urethral orifice. In addition to obesity (body mass index of $38 \mathrm{~kg} / \mathrm{m}^{2}$ ) and the presence of a large incisional hernia (Figure 1A and $\mathrm{B}$ ), pelvic magnetic resonance imaging demonstrated CUD (Figure 2A and B).

The urodynamic study demonstrated a Valsalva leak point pressure of $58 \mathrm{cmH}_{2} \mathrm{O}$ during the Valsalva maneuver at a bladder capacity of $200 \mathrm{~mL}$. The other urodynamic parameters were normal.

\section{Patient 2}

A 70-year-old female developed recurrent cystitis, dyspareunia, dribbling, and SUI. For 4 years, the patient reported daily SUI (several spoons full). She used 4 pads per day and had an ICIQ-short form score of 17.

Physical examination demonstrated a body mass index of $35 \mathrm{~kg} / \mathrm{m}^{2}$ as well as the presence of an incisional hernia occupying the full extent of the median incision scar from anterior surgery and the projection of umbilical scar to the pubic symphysis (due to anterior abdominal radical hysterectomy) with the presence of bowel (Figure 3).

The vaginal examination provided evidence for a loss of dribbling upon coughing and grade 1 cystocele.

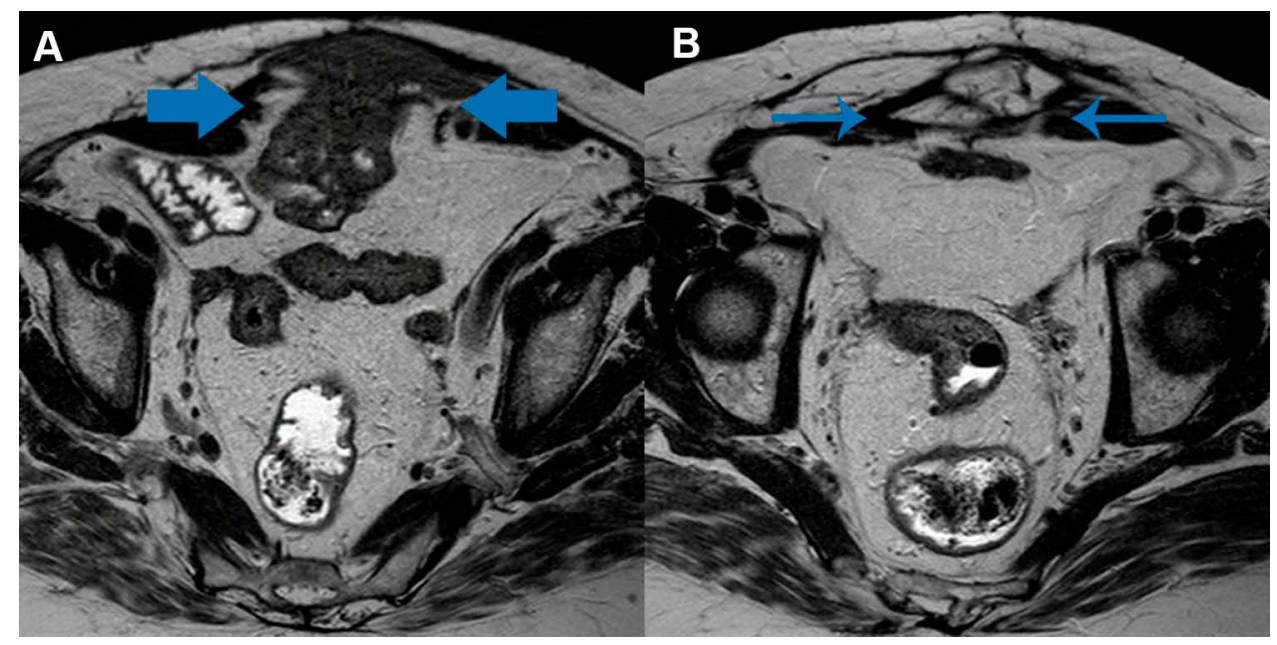

Figure I Magnetic resonance images showing a large incisional hernia with the presence of bowel (A, arrows) and omentum (B, arrows). 


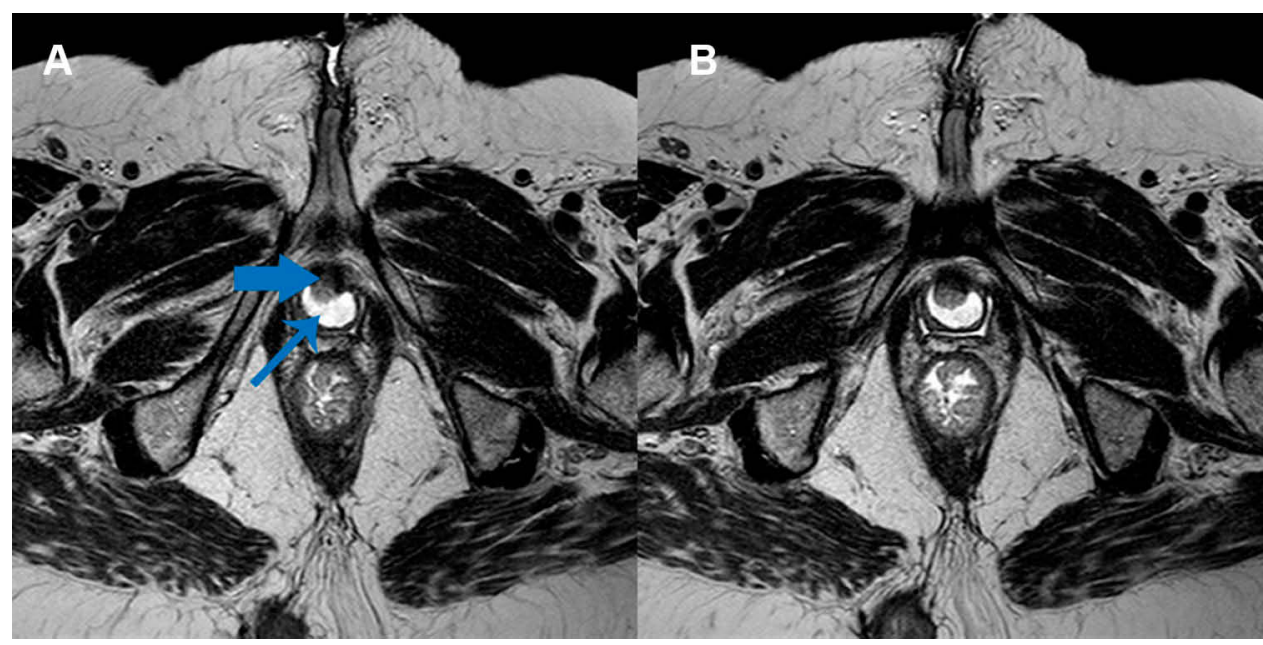

Figure 2 Magnetic resonance image of the pelvis.

Notes: (A) Axial slice demonstrating a complex urethral diverticulum. The small arrow points to the diverticulum lumen. The broad arrow indicates to the urethra. (B) Axial slice of the caudal area of the urethral diverticulum.

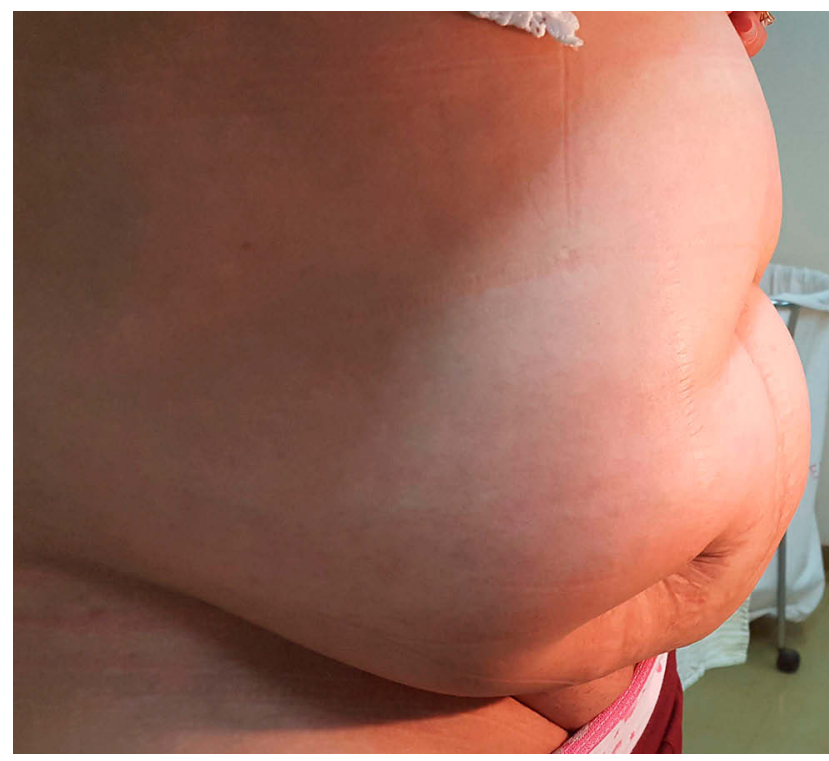

Figure 3 Image of the patient's abdomen in the standing position demonstrates an incisional hernia projecting from the umbilical scar to the pubic symphysis.

Additionally, it demonstrated a mass of approximately $3 \mathrm{~cm}$ in size that could be palpated in the anterior vaginal wall without mobility but with fibroelastic consistency.

The vaginal ultrasound indicated a $3 \mathrm{~cm}$ horseshoe cystic lesion involving the urethra without defined continuity with the urethral orifice (Figure 4), and the voiding cystourethrogram results showed complex horseshoe UD at the midurethral level (Figure 5).

The Valsalva leak point pressure was $61 \mathrm{~cm} \mathrm{H}_{2} \mathrm{O}$ at a bladder capacity of $200 \mathrm{~mL}$. The other urodynamic parameters were normal, except $\mathrm{Qmax}=13 \mathrm{~mL} / \mathrm{s}$ combined $\mathrm{P}_{\text {det }}: \mathrm{Qmax}=26 \mathrm{~cm} \mathrm{H}_{2} \mathrm{O}$, and PVR $=45 \mathrm{~mL}$. A small

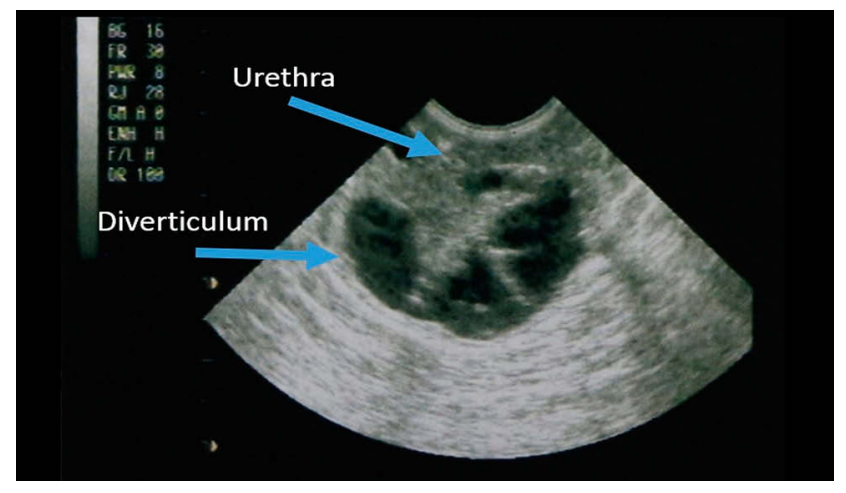

Figure 4 Transvaginal ultrasound axial view shows complex urethral diverticulum as hypoechoic region around urethra.

number of patients may have evidence of bladder outlet obstruction in urodynamic exam due to the obstructive or mass effects of the UD on the urethra. ${ }^{5}$ It should also be reported that SUI may coincide with obstruction. Urodynamically defined SUI and bladder outlet obstruction can coexist in women, nevertheless both conditions can be treated successfully with a carefully planned and executed operation. ${ }^{5}$

\section{Surgical Technique}

Staged procedures could have been executed, but considering the risk of worsening SUI and the fact that there is no consensus on the ideal management strategy, simultaneous treatment of complex UD and SUI was proposed. As the hernia protruded through an infraumbilical failure and its content covered the suprapubic area, the retropubic sling technique and the harvesting of the rectus abdominal 

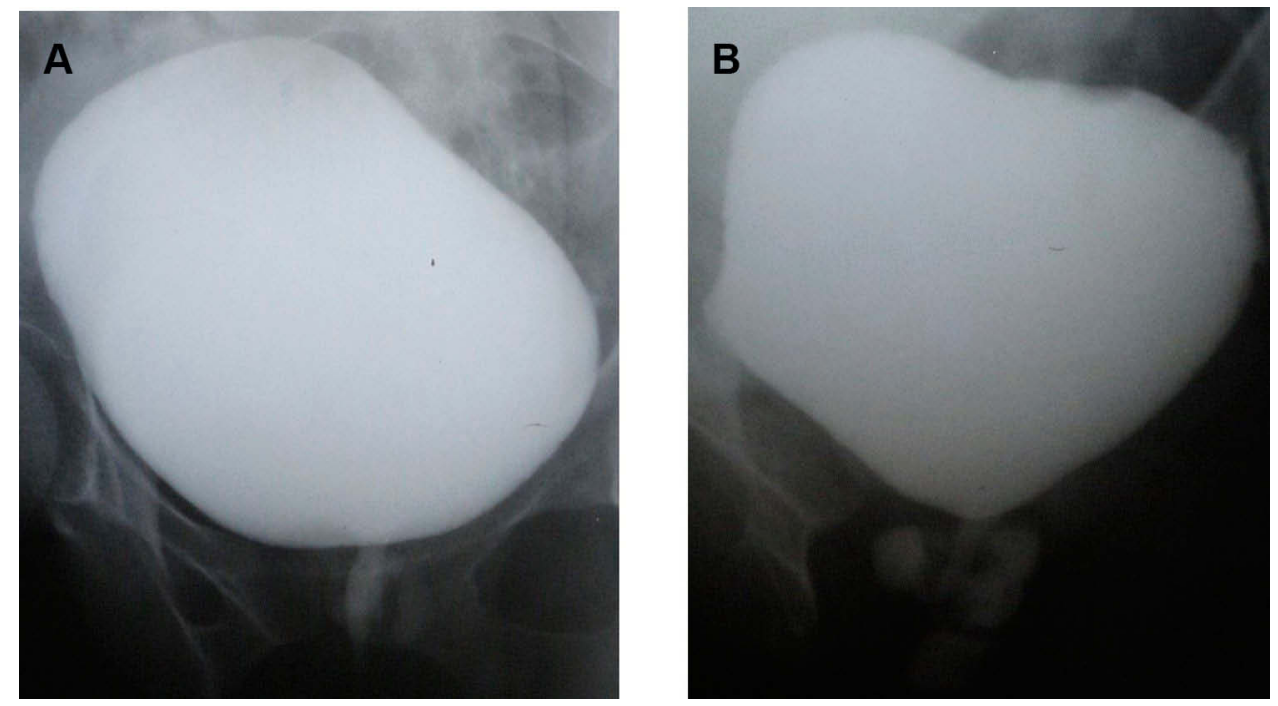

Figure 5 Voiding cystourethrogram shows a complex multilocular diverticulum filled with contrast agent at the level of the midurethra. Notes: (A) Anteroposterior image; (B) oblique image.

aponeurosis band were prohibited due to the risk of visceral lesions. ${ }^{7,8}$

We opted for the use of an autologous sling from the fascia lata; a segment approximately $12 \mathrm{~cm}$ in size of the fascia lata was needed in order to penetrate beyond the muscular wall of the obturator foramen. Consequently, this longer lower limb incision needed for an extended segment increased the risk of muscle hernia and aesthetic damage.

Another alternative would be to use longer prolene or nylon sutures instead of supplementing with fascia, but tension loss may occur and, consequently, sling failure. Therefore, we extended both extremities with polypropylene mesh for proper fixation through the obturator fascia with the use of a hybrid sling.

The local ethics committee (Universidade Estadual de Londrina) approved the study (number 223/09). The authors provided patients with information about different surgeries options and discussed the pros and inherent cons (morbidity, possible complications, restrictions of activities, and hospitalization time) of such treatments. The goal was to make the clinical aspects of the intended procedure clear and to reinforce that Sling hybrid would be a novel technique. The authors explored the patient's ideas and expectations, fear, motivations, to help balance beliefs with realities, a clear statement that written informed consent (included consent to publish the case details, and any accompanying images) was provided and signed by the patients. They decided for one-step surgery.

The proposed surgery was performed under spinal anesthesia and with $1 \mathrm{~g}$ of intravenous cefazolin. The technique used for obtaining the fascia lata ${ }^{10}$ followed the protocol established in the literature. The patient was placed in the supine position with the leg internally rotated at the hip. The thigh was prepped from below the knee to the anterior superior iliac spine. The anterior superior iliac spine (greater trochanter) and lateral femoral condyle were identified and marked. These landmarks are used to identify the proximal and distal attachments of the fascia lata. Two 3-cm horizontal incisions were made approximately $2 \mathrm{~cm}$ (over the iliotibial band) and $6 \mathrm{~cm}$ above the patella. Dissection was carried down to the level of the fascia lata; two parallel incisions were made $2 \mathrm{~cm}$ apart, perpendicular to the skin incision in the direction of the fascial fibers. The undersurface of the fascia was dissected off the muscle as far as possible using both skin incisions. The two parallel incisions were then connected, and this end of the graft was sectioned (Figure 6).

The wound was closed by suturing the following 3 layers without closing the fascia: the subcutaneous tissue, separate dermal closure, and skin. A compressive dressing was applied, and the graft was immediately placed into a basin of sterile saline for later use during sling placement.

The patients were re-prepared and draped in a lithotomy fashion, and diverticulectomy was performed with an ellipsoid vaginal incision (Figure 7A). The UD was grasped and dissected circumferentially down to the ostium (Figure 7B). The urethra was closed with running $4 / 0$ absorbable sutures. The periurethral fascia were closed with $3 / 0$ interrupted absorbable sutures perpendicular to the urethral closure (Figure 7C). The vaginal wall flap was 


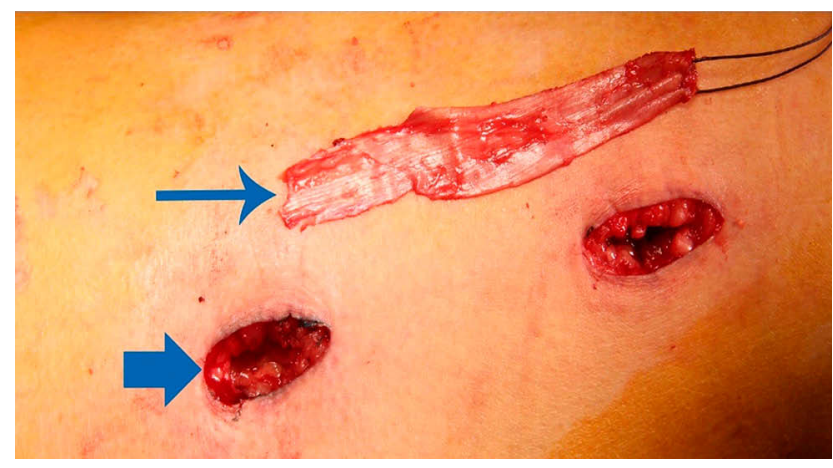

Figure 6 Image of two 2-cm horizontal incisions (over the iliotibial band and $6 \mathrm{~cm}$ above the patella) with the fascia lata strip.

sutured in a running-locking fashion with $2 / 0$ absorbable sutures. After that, the vaginal part of the procedure was carried out with the standard TOT technique, and the urinary bladder was evacuated completely before the insertion of needles. The TOT needles were passed in an in-out fashion, and an approximately $6 \mathrm{~cm}$ segment of fascia lata was fixed to the mesh with prolene $2 / 0$ sutures. At the end of the procedure, the sling was manipulated so that its middle part (fascia) rested directly below the urethra, considering the chances of erosion with an SS (Figure 8).

Cystoscopy was used to look for bladder perforation. The patients were discharged on postoperative day 1 , and the Foley catheter was withdrawn after 14 days. The patients had no lower urinary tract symptoms.

After 6 months postoperatively, patients showed significant improvement in urinary symptoms. They had no storage symptoms, they had ICIQ-SF scores $=0$, there was no stress urinary incontinence, and they had a $1 \mathrm{hr}$ pad test score $<1 \mathrm{gm}$. The postoperative voiding cystourethrogram results were negative for contrast urethral extravasation. The patients had no mesh-related complications. One woman was scheduled for hernia repair at a different date, and another refused treatment.
Table 1 shows 1 year post-operative assessment voiding function. One of the patients does not have an active sex life, and the other has no complaints regarding sexual activity after surgery; on the contrary, it improved with continence. There was no detailed analysis of blood loss, but none of the patients required a transfusion. The surgical time was 90 mins and 100 mins, respectively, and compared to cases of diverticulectomy with Martius flap, there was no longer time.

Hospitalization was $24 \mathrm{hrs}$, and postoperatively patients reported being able to walk with low pain and were pain-free at the harvest site by postoperative day 7 .

\section{Discussion}

There is no consensus on the standard management for SUI associated with CUD. Some series are proposing the selective indication of concomitant anti-incontinence surgery ${ }^{3,4,6}$ and with others recommending delayed treatment for any subsequent instance of SUI. ${ }^{11,12}$

However, if concomitant management is utilized, the use of synthetic mesh is contraindicated considering the risks of infection, like UD recurrence, urethrovaginal fistula, and mesh erosion. ${ }^{7}$ Proponents of concomitant repair cite the benefits, including avoidance of a subsequent anesthetic procedure, use of the autologous sling as an "interposition graft", and the reported safety and efficacy. ${ }^{6}$

Although, only a small number of studies have described the management of SUI in this scenario. The simultaneous procedure has been reported by Faerber $^{13}(n=16)$, Migliari et $\mathrm{al}^{14}(\mathrm{n}=32)$, and Enemchukwu et $\mathrm{al}^{6}(\mathrm{n}=38)$, with continence rates of $90 \%, 87.5 \%$, and $90 \%$, respectively. While no sling erosion or urethrovaginal fistulae were observed over a shortterm follow-up period, the results suggest the temporary retention of urine requiring prolonged periods of catheterization (median 5 weeks) and de novo symptoms of overactive bladder

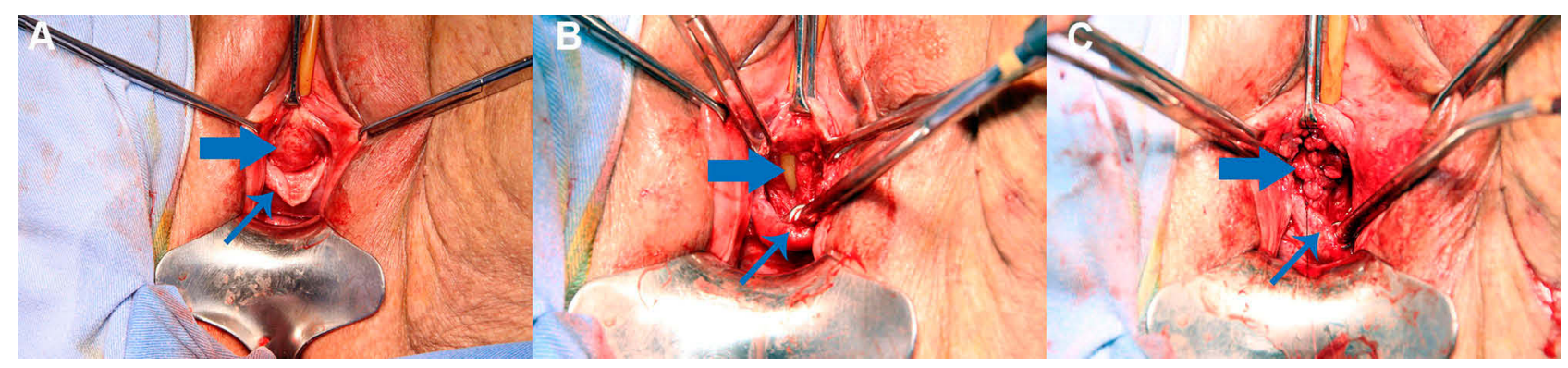

Figure 7 Images demonstrating diverticulectomy

Notes: (A) UD (urethral diverticulum) dissected (broad arrow) and vaginal wall opened (small arrow). (B) UD resected and Foley catheter (broad arrow) and vaginal wall (small arrow). (C) Closure in three layers (urethral mucosa, pubocervical fascia - broad arrow; and vagina - small arrow). 


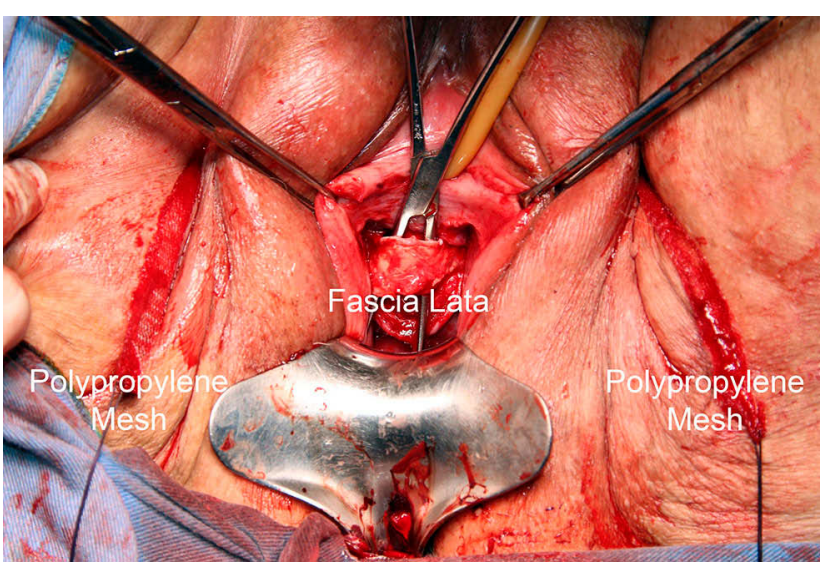

Figure 8 Final aspect of the procedure.

Notes: The synthetic extension of the sling establishes the correct allocation through the obturator fascia. Conversely, the autologous segment decreases the risk of extrusion or erosion.

(5-34\%). Table 2 demonstrates a literature review of simultaneous SUI and diverticulum repair. ${ }^{6,13-16}$

The fundamental argument of staged treatment is that secondary anti-incontinence surgeries are necessary for only a small number of patients. ${ }^{12,17,18}$ Barrat et $\mathrm{al}^{12}$ demonstrated that it was necessary to treat 2.5 women to prevent one case of persistent SUI, so upfront incontinence treatment may result in significant overtreatment.

Simultaneous sling should be avoided in any patient with a contraindication to pubovaginal sling (PVS), including pure urgency incontinence, any other potentially obstructing process, patients with an acontractile or poorly contractile bladder with incomplete emptying or urinary retention.

The literature demonstrates that trans-obturator (TOT) slings are less obstructive than PVS, and there are no series with TOT slings concomitant with diverticulectomy. ${ }^{8}$

It is uncertain whether anatomic configuration is correlated with symptoms, presentation, or outcomes. Stav et $\mathrm{al}^{7}$ suggested that the nature and severity of presenting symptoms were not reliable for distinguishing simple from complex UD, but proximal UD and a size larger than $3 \mathrm{~cm}$ are significantly associated with the development of de novo SUI following UD excision. Thus, preoperative imaging should be achieved to assess the anatomic conformation and definitive operative plan.

The results of Nickles et $\mathrm{al}^{3}$ suggested that patients with complex UD were more likely to present with SUI than those with simple UD $(90.9 \%$ vs $56.3 \%$; p $=0.04)$. However, the postoperative outcomes were similar regardless of the anatomic configuration when an adequate surgical technique was used, with all women in the cohort receiving Martius flap interposition.

Martius flap has its morbidity, and additionally, it does not address any coexistent SUI. In that instance, the sling tension was loose, allowing for correction of concomitant SUI as well as periurethral fascial patching preventing recurrence, fistulas. ${ }^{5,15,19}$

A classification system suggested by Leng and McGuire $^{19}$ divides UD into two categories established on

Table I One-Year Post-Operative Assessment Voiding Function

\begin{tabular}{|l|l|l|l|l|l|}
\hline Patient & Flow Rate - Qmax & PVR & Vaginal Exam & ICIQ-Short Form & OAB-v8 \\
\hline $\mathrm{I}$ & $20 \mathrm{~mL} / \mathrm{sec}$ Bell-shaped & $20 \mathrm{~mL}$ & No extrusion & 0, no pads & 2 \\
2 & $19 \mathrm{~mL} / \mathrm{sec}$ Bell-shaped & $30 \mathrm{~mL}$ & No extrusion & 0, no pads & 2 \\
\hline
\end{tabular}

Abbreviations: PVR, post-void residual; ICIQ, International Consultation on Incontinence Questionnaire-Urinary Incontinence Short Form; OAB-v8, overactive bladdervalidated 8-question.

Table 2 Literature Review of Concomitant SUI and Diverticulum Repair

\begin{tabular}{|l|l|l|l|l|l|l|l|l|}
\hline Author & N & $\begin{array}{l}\text { Mean F/U } \\
\text { (Months) }\end{array}$ & $\begin{array}{l}\text { Cure } \\
\text { SUI (\%) }\end{array}$ & $\begin{array}{l}\text { Improved } \\
\text { SUI (\%) }\end{array}$ & Fistula & $\begin{array}{l}\text { De Novo } \\
\text { Urgency }\end{array}$ & $\begin{array}{l}\text { UD } \\
\text { Recurrence }\end{array}$ & $\begin{array}{l}\text { Urinary Retention } \\
\text { (>4 Weeks) }\end{array}$ \\
\hline $\begin{array}{l}\text { Swierzewski and } \\
\text { McGuire }^{15}\end{array}$ & 07 & 17 & 100 & - & 0 & & 1 & NR \\
Faerber $^{13}$ & 32 & 25 & 88 & 12 & 0 & 2 & 2 & 0 \\
*Migliari et al $^{14}$ & 16 & 51 & 80 & NR & 0 & 1 & 2 & 0 \\
Romanzi et al $^{16}$ & 14 & 39 & 100 & - & 0 & 1 & NR & NR \\
Enemchukwu et al $^{6}$ & 38 & 56 & 100 & 23 & 0 & NR & 1 & 1 \\
\hline
\end{tabular}

Note: *Recurrent pseudodiverticulum.

Abbreviations: F/U, follow-up; NR, not directly reported; SUI, stress urinary incontinence; UD, urethral diverticulum. 
the presence or absence of a preserved periurethral fascial layer. In some patients with UD who have undergone prior vaginal or urethral surgery, the periurethral fascial layer may be deficient, resulting in pseudodiverticulum. ${ }^{19,20}$ These authors propose that the recognition of this anatomic configuration has essential implications for surgical reconstruction, and CUD may require additional reconstruction or the interposition of a tissue flap or graft for reconstruction. ${ }^{18,20}$

The evaluation of the results of a novel surgical technique should be adequately studied with functional analyses, with more patients and over a long period of followup. However, it is promising and rational (based on the use of rectus fascia associated a diverticulectomy in the literature) a urethral diverticulectomy associated with slightly obstructive autologous sling, such as transobturator sling, for treatment of UD with SUI in selected cases.

\section{Disclosure}

The authors report no conflicts of interest in this work.

\section{References}

1. El-Nashar SA, Bacon MM, Kim-Fine S, et al. Incidence of female urethral diverticulum: a population-based analysis and literature review. Int Urogynecol J. 2014;25:73-79.

2. Crescenze IM, Goldman HB. Female urethral diverticulum: current diagnosis and management. Curr Urol Rep. 2015;16:71-75. doi:10. 1007/s11934-015-0540-8

3. Nickles SW, Ikwuezunma G, MacLachlan L, et al. Simple vs complex urethral diverticulum: presentation and outcomes. Urology. 2014;84:1516-1519. doi:10.1016/j.urology.2014.07.070

4. Greiman A, Rittenberg L, Freilich D, et al. Outcomes of treatment of stress urinary incontinence associated with female urethral diverticula: A selective approach. Neurourol Urodyn. 2018;37:478-484. doi:10. $1002 /$ nau. 23334

5. Rovner ES. Urethral diverticula: a review and an update. Neurourol Urodyn. 2007;26:972-977. doi:10.1002/nau.20434

6. Enemchukwu E, Lai C, Reynolds WS, et al. Autologous pubovaginal sling for the treatment of concomitant female urethral diverticula and stress urinary incontinence. $J$ Urol. 2015;85:1300-1303. doi:10.1016/j. urology.2015.02.022
7. Stav K, Dwyer PL, Rosamilia A, et al. Urinary symptoms before and after female urethral diverticulectomy-can we predict de novo stress urinary incontinence? J Urol. 2008;180:2088-2090. doi:10.1016/j. juro.2008.07.049

8. Kobashi KC, Albo ME, Dmochowski RR, et al. Surgical treatment of female stress urinary incontinence: AUA/SUFU guideline. $J$ Urol. 2017;198:875-883. doi:10.1016/j.juro.2017.06.061

9. El-Gamal O, Soliman M, Tawfik A, et al. Use of autologous rectus fascia in a new transobturator hybrid sling for treatment of female stress urinary incontinence: a pilot study. Scand J Urol. 2013;47:5762. doi:10.3109/00365599.2012.700319

10. Blaivas JG, Simma-Chiang V, Gul Z, et al. Surgery for stress urinary incontinence: autologous fascial sling. Urol Clin North Am. 2019;46:41-52. doi:10.1016/j.ucl.2018.08.014

11. Ganabathi K, Leach GE, Zimmern PE, et al. Experience with the management of urethral diverticulum in 63 women. $J$ Urol. 1994;152:1445-1452. doi:10.1016/S0022-5347(17)32442-4

12. Barratt R, Malde S, Pakzad M, et al. The incidence and outcomes of urodynamic stress urinary incontinence in female patients with urethral diverticulum. Neurourol Urodyn. 2019;38:1889-1900. doi:10. 1002/nau. 24090

13. Faerber GJ. Urethral diverticulectomy and pubovaginal sling for simultaneous treatment of urethral diverticulum and intrinsic sphincter deficiency. Tech Urol. 1998;4:192-197.

14. Migliari R, Pistolesi D, D'Urso L, Muto G. Recurrent pseudodiverticula of female urethra: five-year experience. Urology. 2009;73:12181222. doi:10.1016/j.urology.2008.07.040

15. Swierzewski SJ 3rd, McGuire EJ. Pubovaginal sling for treatment of female stress urinary incontinence complicated by urethral diverticulum. J Urol. 1993;5:1012-1014. doi:10.1016/S0022-5347(17) 36283-3

16. Reeves FA, Inman RD, Chapple CR. Management of symptomatic urethral diverticula in women: a single-centre experience. Eur Urol. 2014;66:164-172. doi:10.1016/j.eururo.2014.02.041

17. Lee UJ, Goldman H, Moore C, et al. Rate of de novo stress urinary incontinence after urethral diverticulum repair. Urology. 2008;71:849853. doi:10.1016/j.urology.2007.11.138

18. Leng WW, McGuire EJ. Management of female urethral diverticula: a new classification. $J$ Urol. 1998;160:1297-1300. doi:10.1016/ S0022-5347(01)62520-5

19. Zhou L, Luo DY, Feng SJ, et al. Risk factors for recurrence in female urethral diverticulectomy: a retrospective study of 66 patients. World J Urol. 2017;35:139-144. doi:10.1007/s00345-016-1815-5

20. Porpiglia F, Destefanis P, Fiori C, et al. Preoperative risk factors for surgery female urethral diverticula. Our experience. Urol Int. 2002;69:7-11. doi:10.1159/000064352
Research and Reports in Urology

\section{Publish your work in this journal}

Research and Reports in Urology is an international, peer-reviewed, open access journal publishing original research, reports, editorials, reviews and commentaries on all aspects of adult and pediatric urology in the clinic and laboratory including the following topics: Pathology, pathophysiology of urological disease; Investigation and treatment of urological disease; Pharmacology of drugs used for the treatment of urological disease. The manuscript management system is completely online and includes a very quick and fair peer-review system, which is all easy to use. Visit http://www.dovepress.com/ testimonials.php to read real quotes from published authors. 